Proceedings of the Institution of Civil Engineers - Construction Materials 174(2): 67-68,

\title{
Construction Materials
}

\section{ice Publishing}

\section{Editorial}

\author{
Mario R. de Rooij PhD (Eng)
}

TNO, Delft, the Netherlands

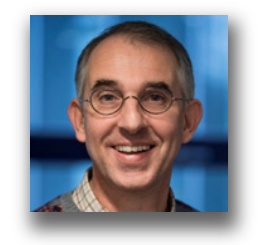

The Suez Canal is in every major headline of the news at the time of writing of this editorial. A large container ship, the Ever Given, has caused a massive traffic jam in one of the world's major shipping routes. The $400 \mathrm{~m}$ long ship (roughly as long as the 23 Marina building in Dubai is tall) has completely blocked the $215 \mathrm{~m}$ wide canal. By the time this editorial gets published, it will be known how much effort and how many days it has taken to unblock the Suez Canal.

A curious side-effect of this story may be that many more people will know where the Suez Canal is located exactly. For convenience, a map of the area is provided in Figure 1.

As a coincidence, the four papers in this issue of Construction Materials happen to be from authors of that same region. In this issue we serve you papers from authors out of Egypt, Jordan, Saudi Arabia and Iran. We hope that the names of the authors and their good-quality papers will be remembered much longer than the current blockade of the Suez Canal.

As condensed as the region of our authors is, as wide is the variety of their topics. We are proud to publish papers on all construction materials and this issue expands to all the different materials corners. From Egypt we look towards asphalt mix design; from Jordan we learn about recycled waste glass in concrete; from Saudi Arabia we study predictive models for steel-fibre-reinforced concrete (SFRC) beams; from Iran we analyse wrappings of carbon-fibre-reinforced polymer (CFRP) composites on steel-plate girders. Hence, there should be at least one paper that matches your materials science interest.

The first paper in this issue is by Mousa et al. (2021). They draw our attention to optimising the asphalt content in the design of a hot asphalt mix. This is important because the amount of asphalt plays a major role in the properties and hence the performance and durability of the road infrastructure. If the asphalt content is too high, this will lead to rutting, flushing and insufficient air voids in the asphalt mix. On the other hand, if the asphalt context is too low, this will lead to a harsh mix that is hard to compact which can lead to durability problems.

In their article Mousa et al. study the asphalt content for different aggregate gradations to come up with a predictive model to significantly reduce the amount of trial mixes that

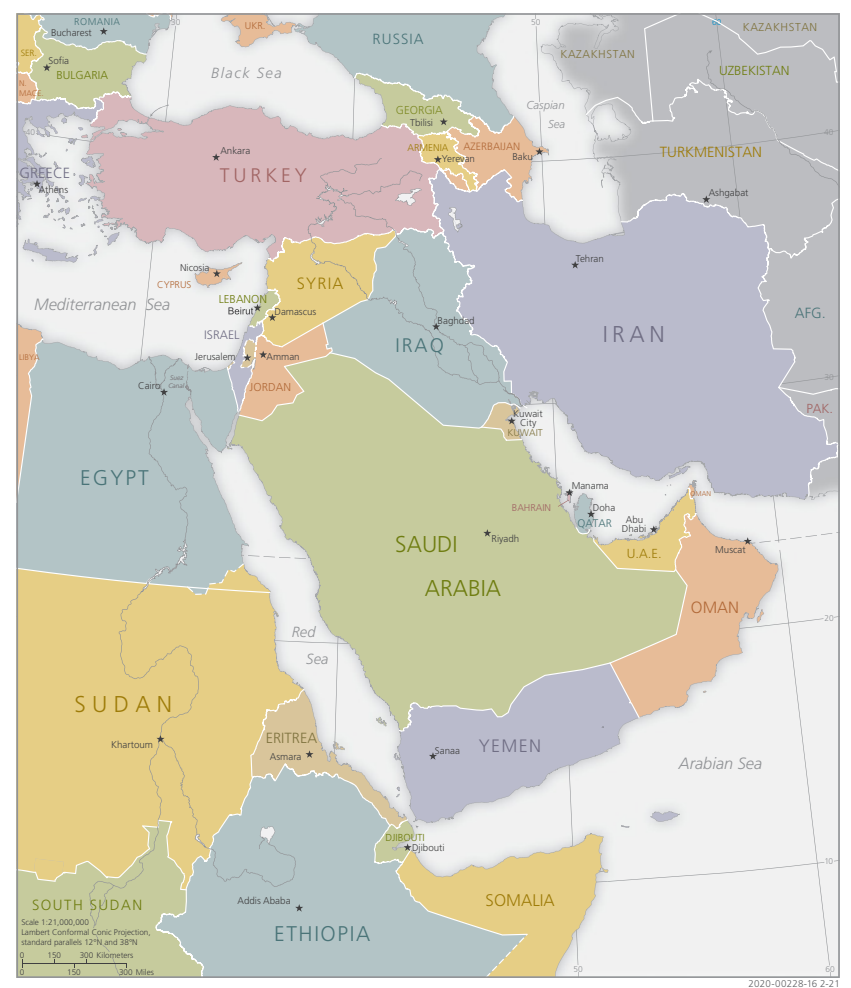

Figure 1. Middle East region 
are nowadays required for estimating the optimum asphalt content.

The second article is by Abendeh et al. (2021). In this article the attention is on glass recycling, in particular on waste glass. Waste glass represents about $5 \%$ of domestic waste. As an example, in 2013, 11.54 Mt of waste glass was generated in the USA (US EPA, 2015). It leads Abendeh et al. to study the production of durable concrete by incorporating waste glass as a partial replacement of fine aggregates or Portland cement. They classify the waste glass in their investigation as glass powder or crushed glass aggregates.

The article is rich in data and shows that the properties of concrete can be enhanced through this waste glass, but only up to a point.

The third article takes us, with a most interesting approach, into the world of predictive models. Here Islam (2021) focuses on the prediction of shear strength of SFRC beams. He has compiled a database based on 21 existing experimental studies going back from 2010 until 1972, resulting in data of 222 beams. Based on past investigations, it is shown that a significant gain in the shear strength of SFRC beams can occur due to an increase in compressive strength, the ratio of the tensile reinforcement, the amount of fibres and a decrease in the beam's span-depth ratio. However, existing models often under- or overestimate the shear capacity of SFRC beams when compared to experimental data.

Hence, Islam suspects room for improvement and uses a genetic algorithm to come up with a better predictive model. Read his article to see how and where these types of models can improve predictions.

The last article of this issue remains in the modelling area. Azizi et al. (2021) investigate the shear strengthening of steel-plate girders using CFRP composites. They report both on the experiments and on the model verification. In the research, 11 specimens with different arrangements of composite strips on the web of the plate girders were investigated.

Please read their story and learn that the location and arrangement of the CFRP plates on both sides of the web do have an influence.

We hope that with this issue of Construction Materials we have brought you a nice selection of interesting topics. Please note that we do publish our most recent articles online in the ICE Virtual Library: look in the 'Ahead of Print' section under the 'Volumes and Issues' heading on the Construction Materials page.

\section{REFERENCES}

Abendeh RM, AbuSalem ZT, Bani Baker MI and Khedaywi TS (2021) Concrete containing recycled waste glass: strength and resistance to freeze-thaw action. Proceedings of the Institution of Civil Engineers - Construction Materials 174(2): 75-87, https://doi.org/10.1680/jcoma.17.00065.

Azizi S, Mehmandoost Kotlar H and Narmashiri K (2021) Shear strengthening of plate girders using carbon-fibre-reinforced polymer composites. Proceedings of the Institution of Civil Engineers - Construction Materials 174(2): 101-111, https://doi.org/10.1680/jcoma.16.00078.

Islam MS (2021) Simplified shear-strength prediction models for steel-fibre-reinforced concrete beams. Proceedings of the Institution of Civil Engineers - Construction Materials 174(2): 88-100, https://doi.org/10.1680/jcoma.16.00073.

Mousa KM, Abdelwahab HT and Hozayen HA (2021) Models for estimating optimum asphalt content from aggregate gradation. Proceedings of the Institution of Civil Engineers - Construction Materials 174(2): 69-74, https://doi.org/10.1680/jcoma.18.00035. US EPA (United States Environmental Protection Agency) (2015) Advancing Sustainable Materials Management. Fact Sheet. United States Environmental Protection Agency, Washington, DC, USA, EPA530-R-15-003. 